Article

\title{
Technology and School Unit Improvement: Researching, Reconsidering and Reconstructing the School Context through a Multi-Thematic Digital Storytelling Project
}

\author{
Theodora K. Kouvara ${ }^{1, *}$, Stavroula A. Karasoula ${ }^{2}$, Christoforos V. Karachristos ${ }^{3}$, \\ Elias C. Stavropoulos ${ }^{3}$ and Vassilios S. Verykios ${ }^{4}$ \\ 1 Department of Education, School of Education, University of Nicosia, 46 Makedonitissas Avenue, \\ Nicosia CY-2417, Cyprus \\ 2 Department of Humanities, School of Humanities, Hellenic Open University, 18 Parodos Aristotelous Str., \\ GR-263 35 Patras, Greece; std103411@ac.eap.gr \\ 3 Methodology \& Technology Laboratory, Educational Content, Hellenic Open University, 52-56 Kalavriton \\ Str., GR-263 34 Patras, Greece; karachrist@eap.gr (C.V.K.); estavrop@eap.gr (E.C.S.) \\ 4 School of Science and Technology, Hellenic Open University, 18 Parodos Aristotelous Str., GR-263 35 Patras, \\ Greece; verykios@eap.gr \\ * Correspondence: Theodorakouvara@gmail.com
}

Received: 29 December 2018; Accepted: 2 February 2019; Published: 6 February 2019

\begin{abstract}
Digital stories comprise a technological tool which can engage learners in collaborative learning as well as lead them to experientially acquire knowledge through a constructive process. The aim of the current action research, for which a cooperative network between academics and teachers was created, is to show how digital storytelling can emerge as an inclusive education tool through investigating the changes brought about by its implementation on the academic and social context of a school unit. The research was conducted in a Greek primary school and lasted seven months, involving two fifth grade classes and an integration class. It followed the three stages of a multi-thematic digital story project (preparation, implementation, and evaluation) and learners were called to research and process information, at their own pace, from diverse cognitive domains (art, science, coding). The research tools employed were participatory observation, diary research, and semi-structured interviews. The research positively influenced the reconstruction of the school unit since teachers reconsidered some of their educational techniques as non-inclusive, utilized technology as an instrument of constructive and experiential learning based on the diversity of each student, and reinforced learners' critical thinking and imagination while cultivating a climate of empathy and self-confidence among students.
\end{abstract}

Keywords: action research; critical thinking; inclusive education; school networks; student engagement

\section{Introduction}

Modern trends in education and, especially, in special needs education require and essentially demand the creation of a school open to diversity. In specifics, supporting students with special needs and social behavior problems has become a necessity which, according to September (2008), is dictated by moral, educational, and legal reasons. After the Salamanca Statement in 1994, which called for the inclusion of all students in regular schools to be the norm, the approach of inclusive education was adopted, requiring that ordinary schools accommodate all children, and that every child attend the 
neighborhood school ( $\sum \tau \alpha \sigma \downarrow v o ́ \varsigma$ 2016). Hence, teachers should develop skills and knowledge towards a more inclusive culture (A $\gamma \alpha \lambda \iota \dot{\tau} \tau \eta$ 2011) $^{2}$

In inclusive education, children with academic and social difficulties are not separated from their classmates $(A \gamma \gamma \varepsilon \lambda i \delta$ ov 2011). The purpose of inclusion is to create the appropriate conditions for each student to get equal opportunities in learning ( $\Sigma \tau \alpha \sigma \iota v o ́ s ~ 2016)$. Therefore, the teacher should create a learning environment that prioritizes the academic and social needs of all children, aiming at the fair and democratic functioning of the school (A $\gamma \gamma \varepsilon \lambda i \delta \eta \zeta$ and Ev $\alpha \gamma \gamma \varepsilon$ é $\lambda$ ov 2012). Educators have to act flexibly and reconstruct their tuition, by diversifying it in the best possible way (use of teaching aids and digital methods, appropriate adaptation of the curriculum to the learners' needs and interests), thus building an experiential and flexible learning environment based on the needs of each school context. According to literature review, technology can greatly aid towards that direction

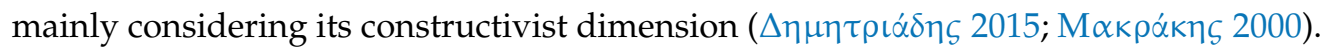

As technology emerges as a basic educational tool, the aim of the current research is to explore the extent to which a multi-thematic digital storytelling project can emerge as a basic tool of inclusive education through investigating the changes brought about by its implementation on the academic and social context of a school unit. To this end, the following research questions were posed:

1. How can this multi-thematic digital storytelling project motivate learners' critical thinking by using higher cognitive levels of thought?

2. How can the current project promote the adoption of a teaching approach which takes into consideration the needs and uniqueness of each learner?

3. How can the specific project lead to creating collaboration networks within the school unit?

Although ICT technologies have provided a novel and fertile ground for learning and teaching purposes, many Greek teachers hold a negative stance towards using educational technology as its use is deemed to be restricted on ICT lessons while its use in special needs classrooms is also considered

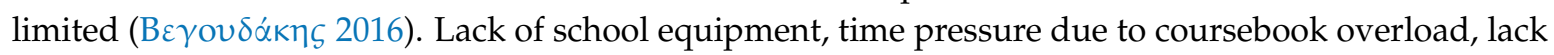
of confidence, and lack of theoretical and technical knowledge seem to be the main barriers impeding technology integration (Karkoulia 2016; Lee 2000). Most teachers consider that the use of technology should be restricted to the ICT lesson while its use in special needs classes is also considered limited. Due to the limited and one-sided use of technology in education and, especially, in special needs education, the achievement of the current research's aim seems pertinent. The specific research was presented by Kouvara et al. (2018) at the "WEI International Academic Conference on Education, Teaching and Learning" on 1-3 August 2018, in Boston. What follows is the stages and the findings of the research after a brief presentation of the theoretical framework.

\section{Digital Storytelling}

Digital storytelling is not a novel concept in educational technology, thanks mainly to Lambert and Atchley, co-founders of the Center for Digital Storytelling in Berkley, California, in 1993 (Robin 2008). Reaching back to the 80 s, digital stories can be described as short vignettes that have been relying on multimedia elements, including images, video, audio, and text (Ohler 2013).

Given that storytelling is "older than human history itself", the power of stories has been significant through generations, since they represent one of the oldest forms of education (Czarnecki 2009 , p. 10). Always at the heart of education, they hold a magical quality which can engage learners in a unique way that few other educational methods can. Still, when storytelling migrates to the digital realm, riding the adventure of emerging technology seems to be a digital story on its own. Storytellers always used to avail themselves of the latest technology available to share their creations since, instead of merely being a tool to spread stories, technology aids in expanding their audience, thus constituting a deeply integrated part of the storytelling process (Czarnecki 2009).

Needless to say, the digital tools currently abound and facilitate the storyteller to utilize these elements to narrate an effective story. Storytelling does not only fit in a language arts course but spans 
the whole curriculum, thus letting learners uncover novel ideas while assembling resources for their digital stories. Ohler (2013) argues that digital storytelling seems to be the most suitable vehicle for blending traditional and emerging literacy development, while learners are required to "synthesize imagination, creativity, research and critical thinking" so as to "translate their ideas into some form of media-based expression" (p. 13).

The core theory underlying digital storytelling is that of constructivism, which allows learners to construct new knowledge and employ critical and reflective thinking ${ }^{1}$ (Richards 1998) while, according to Teehan (2006), digital storytelling facilitates the convergence of four learner-centered learning strategies, namely, project-based learning, learner engagement, reflection for deep thinking, and the effective integration of technology into the learning process. In this way, learners develop high-order thinking abilities defined by Thorne and Thomas (2007), as thinking on a level higher than memorizing facts or just restating facts. After gathering information, learners engage in processing, modifying, and negotiating information, as well as problem-solving, thus acting as autonomous and independent learners (Teehan 2006). As a consequence, digital storytelling can help create an informal learning environment (A $\gamma \gamma \varepsilon \lambda i \delta \eta \zeta$ and $A \beta \rho \alpha \mu i \delta$ ov 2011). In this way, digital storytelling becomes an inclusive education tool which can adapt learning to the needs of each learner, taking into account the whole (Kouvara et al. 2018). The various possibilities it offers in terms of approaching knowledge (visual, acoustic, experiential), combined with the diverse skills it cultivates-cooperation, leadership role of students, brainstorming of ideas and information, motivation for research, and adaptation to learner's

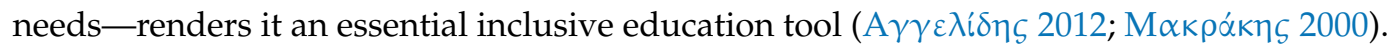

Last but not least, digital storytelling in the classroom not only aids all learners to get engaged in high-order thinking abilities, but also helps them develop various literacies, such as digital, global, computer or technology, visual, information, and media, thus promoting 21st century skills and encompassing multiple literacy skills such as researching, problem-solving, and assessment (Robin 2008).

\section{Methodology}

The research was conducted in a provincial Greek primary school during the time period from 16 September to 30 March in the academic year 2017-2018. It lasted approximately 7 months, and its impact on the school unit was investigated for 2.5 months after its completion. This school was not chosen at random, since it is a school that has a special needs classroom and is one of the few technology-equipped Greek primary schools. In contrast with other Greek schools which lack technological equipment, the specific school is renowned for its emphasis on European lifelong learning programs and its technological equipment, as all classrooms are equipped with projectors and laptops, funded by European programs (Comenius, Erasmus+), local sponsors and parents. It goes without saying that it is a progressive school open to innovative actions which, instead of merely fostering rote learning, promotes research and critical thinking.

A qualitative approach to collecting and studying data was adopted as, according to B $\rho \alpha \sigma i \delta \alpha s$ (2014), qualitative research aims at in-depth study of the context in which the research is conducted, requiring the researcher' presence in the research context. More specifically, the model of participatory action research was adopted, as this model, according to $A \gamma \gamma \varepsilon \lambda i \delta \eta \varsigma$ (2012), aims not only at data recording, but also at reflecting on the practices of those involved in the research with a view to improving them.

A 6th grade cohort, consisting of two classes with 50 eleven-year-old students (25 students in each class), 4 of whom attended the special needs classroom, participated in the research, along with 5 teachers and the school principal. This specific grade was chosen, firstly, because it included

1 The term "critical thinking" used in the current study refers to the activation of the higher cognitive processes of thought, such as analysis, synthesis, and the evaluation of a concept (Thorne and Thomas 2007.) 
students who attended the special needs classroom and, secondly, because students had been taught the Scratch.2 programming language which would be the main technology tool used for creating the

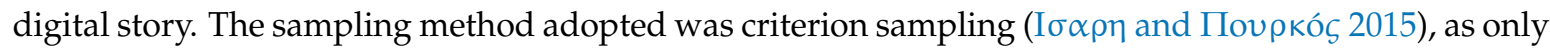
those being involved in the digital story project (pupils and teachers) were the object of the research.

The research team comprised five researchers. The first researcher, who had the role of the coordinator, had previous experience in inclusive education research, and acted as an observer in the classroom of all the teachers who were engaged in the project. She also conducted two phases of recorded semi-structured interviews with the students, the teachers, as well as the school principal, before and after the project. The second researcher was a teacher of the school where the research was conducted, and was in charge of keeping a reflective diary. The third researcher was an ICT researcher, who participated in the research as an observer and was responsible for teaching the Scratch.2 programming language to students and coordinating the coding part of the digital story. The fourth and fifth researchers were academics who had the role of supervisors and advisors throughout the research. All researchers kept a reflective diary. The researchers met and discussed topics which mainly concerned the collaboration between teachers and students involved in the project-issues emerging from the findings-and designed the next course of action.

The data analysis was based on two stages, proposed by $B \rho \alpha \sigma i \delta \alpha \varsigma$ (2014), namely, deductive and inductive. With regard to the inductive stage, cross-functional reasoning was adopted, according to which data findings were organized based on a common classification system (codification) (I $\sigma \alpha \rho \eta$ and Поирко́ s 2015). After the data classification/codification, the data were coded and then grouped, and the first allegations were made ( $\sigma \sigma \iota \dot{\jmath} \lambda \eta \zeta$ 2015). Finally, at the inductive stage, the process of documenting and rejecting allegations from the previous stage was implemented through seeking for evidence from the data collected.

In order to ensure the reliability and validity of the research, two forms of triangulation were followed (Miles and Huberman 1994). In particular, the data were cross-verified through the use of different research tools (observation, interview, reflective diary) and different evaluators (each interviewee could check the transcript of the interview given). With regard to horizontal triangulation, the data were examined by all researchers from many different perspectives (Lincoln and Guba 1985). Also, the technique of analyzing a negative case was adopted with a view to looking for data that

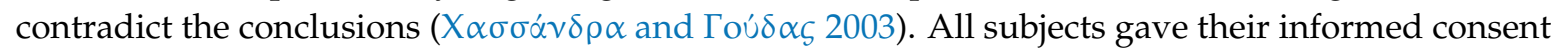
for inclusion before they participated in the study. The study was conducted in accordance with the convention of the United Nations (1989), and the protocol was approved by the Ethics Committee of Institute of the Education Police. Pseudonyms were used for research purposes.

\section{Project}

The researchers employed the project-based framework as it is deemed an innovative approach to learning, allowing in-depth investigation of a specific topic (Sifakis and Georgoutzou 2004). The overall aim of the project was to enable students to create a digital story which would depict climate change through works of art. In specifics, the objectives of the lesson were to develop learners' creativity, cultivate teamwork and cooperation among them, fire their imagination, develop new literacies ${ }^{2}$, and promote real life skills.

A four-and-a-half-month period was the time needed for the completion of the project, which assumed three main procedural stages, namely, planning, presentation, and evaluation (Booth 2002; Dickins and Germaine 2014). One month was devoted to the planning stage, during which the topic

2 New literacies refer to digital literacy (the ability to find, evaluate, utilize, share, and create content using information technologies and internet), media literacy (the ability to synthesize, analyze, and produce mediated messages), visual literacy (the ability to interpret, negotiate, and make meaning from information presented through an image), information literacy (the ability to find, evaluate, and synthesize information), and global literacy (the ability to read, interpret, respond, and contextualize messages from a global perspective (November 2008). 
of the project was decided, and the steps to be followed were planned. The implementation stage was the actual project work and lasted almost two and a half months, while the evaluation phase was conducted in a two-week time period.

\subsection{Planning}

In the first week of the project (25-29 September), researchers, teachers, and students jointly decided that the thematic core of the digital story would focus on the ecological problem. Specifically, in the English language course, the teacher set the scene by initiating a discussion on climate change and recent natural disasters in the area, thus activating schemata and background knowledge. Learners watched videos on global warming and talked about previous relevant projects they had conducted with a view to recalling prior knowledge on the issue and reviewing relevant language. The educational methods employed were mainly centered upon brainstorming and scaffolding learners' answers through questions (Kajder et al. 2005).

Learners were asked to produce something that would capture people's attention regarding the critical issue of climate change. While learners brainstormed ideas on how to raise awareness regarding the issue, works of art by famous artists were presented through the projector and learners, filled in relevant activities, and were asked how they could exploit such works of art in order to awaken people's interest on the issue. The teacher tried to creatively inspire learners and move them into a mindset where they could visualize their story before writing the script, in order to create a story that felt unique and powerful (Lambert 2013).

During the second week (2-6 October), the project was launched, and the learners, researchers, and teachers' action plan was set up. In particular, the time period during which learners along with their teachers would work on the project, the appropriate techniques they would use, as well as that their responsibilities were defined. Considering learners' ideas about this multi-thematic project, it was decided that famous paintings would be utilized as the backdrop of the digital story. In specifics, the causes of the environmental destruction would be exposed in the first part of the story while, in the second part, students, being represented by digital little humans designed through Scratch.2, would search for solutions. Regarding the first part of the story, the backdrop would be photos of famous paintings while, regarding the second part, the backdrop would be recreations of famous paintings made by students, adding three-dimensional features to their creations. The story script would be written and recorded by students.

The Scratch. 2 programming language, with which most students were already acquainted with Video Movie Maker, as well as Audacity software were the technological tools chosen for learners to create and share their digital story. Scratch.2, according to $\Delta \eta \mu \eta \tau \rho \iota \alpha ́ \delta \eta \zeta ~(2015)$, is an appropriate programming environment for children and teenagers based on Lego's ideas. Essentially, photos of students' creations, as well as photos of paintings, would be uploaded into Scratch.2 to be used as backdrop for the Scratch.2 videos students would create. By using Scratch.2, students would give movement to the digital kid who would act in the paintings, by writing the appropriate code and writing the script. In this way, they would produce Scratch.2 videos to be inserted into Movie Maker, and produce a final video with all Scratch.2 videos united.

In the third week (9-13 October), students of both classrooms were divided into groups and assigned roles. The composition of the teams would not remain stable but would vary while creating the digital story, depending on who would take the lead in each group, so that all the students would be team leaders at some point. In specifics, each class consisted of 3 researchers (responsible for searching online material and information), 6 scriptwriters, 5 artists, 3 Scratch programmers, 3 narrators, and 5 scientific analysts. Worth noting is the fact that learners' responses in the interviews conducted (favorite subject, job, hobby) were taken into account, as well as teachers' viewpoints regarding learners' talents and interests. In a similar vein, every team included learners with both high and low academic skills, with a view to forming functional learner teams and fostering a collaboration climate. 
The title of the project "Digital Literature Workshop: The Environment through Art" was selected in the last week (16-20 October) and learners, along with teachers, decided to present their end product in the 8th Digital Festival in May.

Learners and teachers also discussed through the seven elements necessary for creating an effective digital story, namely, point of view, a dramatic question, emotional content, the gift of one's voice, the power of soundtrack, economy, and pacing (Lambert 2013). In specifics, emphasis was given to the driving question of the story which would attract viewers' attention, as well as the emotion evoked by the story which would lead to the audience's emotional engagement. Also, it was clarified to students that their end product would be evaluated according to these seven criteria, thus considering them as benchmarks of performance which would guide them through the project (Dochy et al. 2003).

\subsection{Implementation}

The implementation phase lasted almost ten weeks (16 October-12 January) without the Christmas holidays, and was mainly aimed at familiarizing students with the appropriate learning strategies so as to achieve their objective successfully (Legutke et al. 2014). In specifics, during the first two weeks (16-27 October), the "researcher" team sought online information regarding the ecological problem, presented their findings in the English language course, and discussed with their teacher and classmates how to present the problem and its solutions in their the most effective way.

In the next two weeks (1-17 November), the students who had assumed the "artist" role searched for famous paintings which could depict the ecological disaster and presented them in the classroom along with information regarding the artist. After careful consideration, learners decided to select the following paintings for the first part of their story: "Iron Dome, Eilat" by Uri Blayer, "Seascape, Night Effect" by Claude Monet, "Resist" by Robert Bissell, "Feuerquelle" by Paul Klee, and "Sinbad the Sailor" by Paul Klee.

During that stage, learners gathered, organized, synthesized, and evaluated information with a view to creating a story and sharing their final product. Besides developing visual literacy in their attempt to find meaning with pictures, they learned how to employ learning strategies, such as skimming websites to get the personal gist, scanning in order to find specific information, as well as summarizing and synthesizing the information. They compiled and organized the information needed for the digital story and discarded the irrelevant one. Hence, learners made use of higher-order thinking skills as they thought on a level higher than just restating facts in accordance with Jenkins and Lonsdale (2007) who claimed that a digital storyboard can act as an authentic context for fostering learners' higher-order thinking skills.

Regarding the second part of the story, learners had to choose which paintings would be reconstructed so as to acquire three-dimensional features and special effects. Five paintings were chosen, namely "The Starry Night" by Vincent van Gogh, "The Persistence of Memory" by Salvador Dali, "Ship With Butterfly Sails" by Salvador Dali, "Red Ballon" by Paul Klee, "Jeune Fille Endormie" by Pablo Picasso and "The Meditative Rose" by Salvador Dali. Learners were divided into teams of five learners with the student who had undertaken the "artist" role being the leader. For this, learners of each team tried to ignite their imagination and generate ideas on how to present each painting three-dimensionally. The leader of each team was responsible for reporting the group ideas to the art teacher who, in turn, elaborated on them and provided guidance, help, and support when needed. Every team was in charge of reconstructing one painting of the five selected, and collaborate with the group of the other class which was in charge of the same painting.

In the next two weeks (20 November-1 December), children were given a storyboard and started writing the story script. According to Kajder et al. (2005), the initial step in creating digital stories is writing the initial script and creating the storyboard prior to working with the technology and, hence, learners were prompted to focus on the story first and the digital medium second, so that their story would not get overpowered by technology (Ohler 2006). Hence, before proceeding with 
supplementing the story with multimedia tools, learners drafted, redrafted, and reviewed the story script in order to produce an engaging story (Robin 2008).

During the same time period, learners started recreating the famous works of art in the art lesson. In particular, regarding "Starry Night", learners decided to emphasize the chaotic vortices depicted on the painting by giving them a rotating and three-dimensional form. They used cardboard and created three-dimensional stars (larger than the ones depicted in the original painting), painted them with oil paintings, and pierced them on the painting. They pinned the stars on the painting with large nails which were placed in such a way so that each student could twist a star and give the impression to the audience that the stars rotate.

At the same time, the members of the specific team worked individually and painted the "Starry Night" on A4 sheets of paper. In specifics, they painted the moon and the star-filled night sky while the village and the tree were photocopies of the original painting. The aim of this activity was to produce five paintings which would alternate at a high speed in the digital story, thus creating the illusion that the sky moves, since students painted the sky without the same precision and approached its chaotic vortices based on their visual literacy and not on computational thinking (Figures 1-4).

The second group, the group of "The Persistence of Memory", used a maquette several objects so as to recreate the painting by giving three dimensional features to it. They creased the upper side of the maquette where they painted the sky with olive paints, and used clay to create the craggy rocks. They used clay to create the creature in the middle of the painting, as well as the clocks which were then painted with olive paints. They also used a paper box and pierced it with a small branch of tree to hang the "melting clock" made of clay, so as to approach the painting as much as realistically possible (Figure 5).

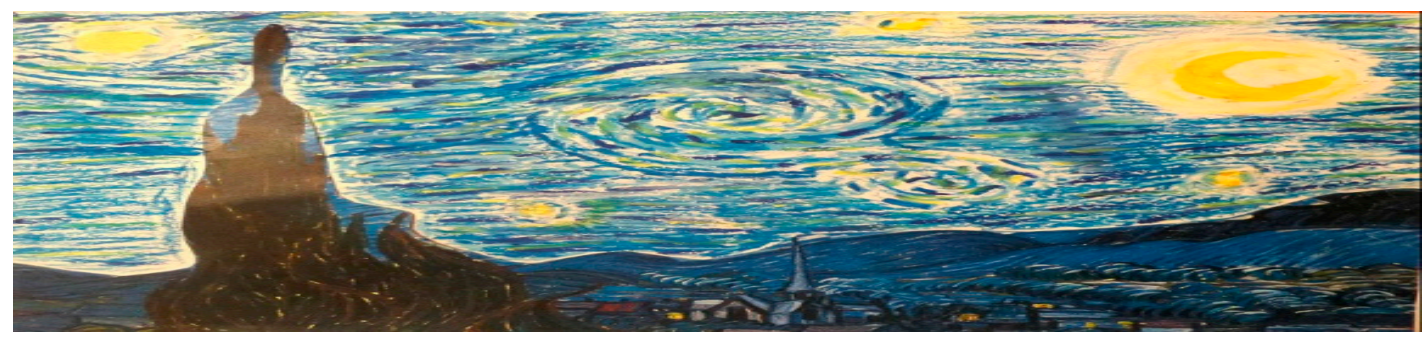

Figure 1. "Starry Night", sketch 1.

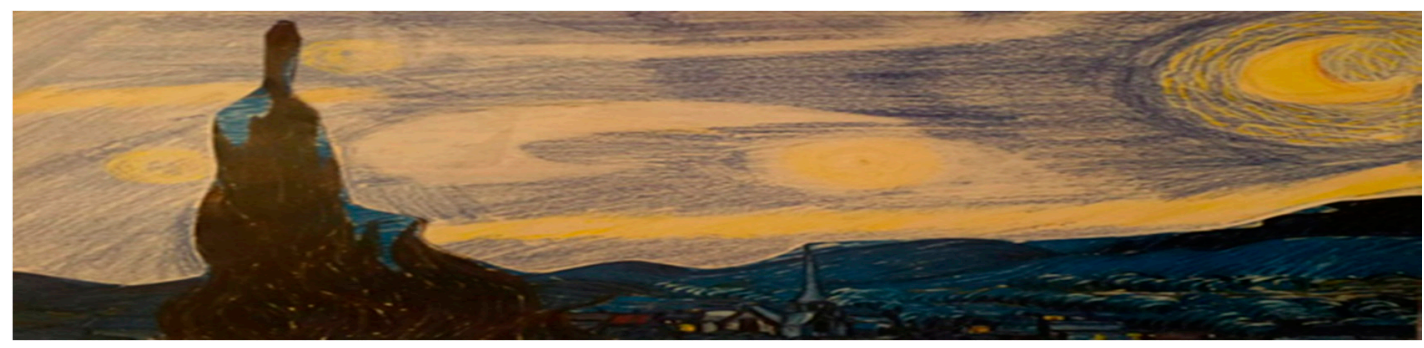

Figure 2. "Starry Night", sketch 2.

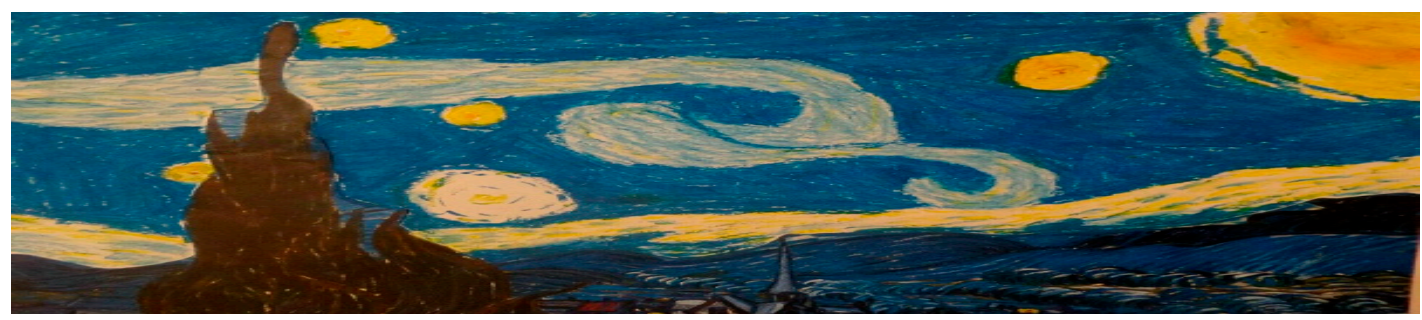

Figure 3. "Starry Night", sketch 3. 


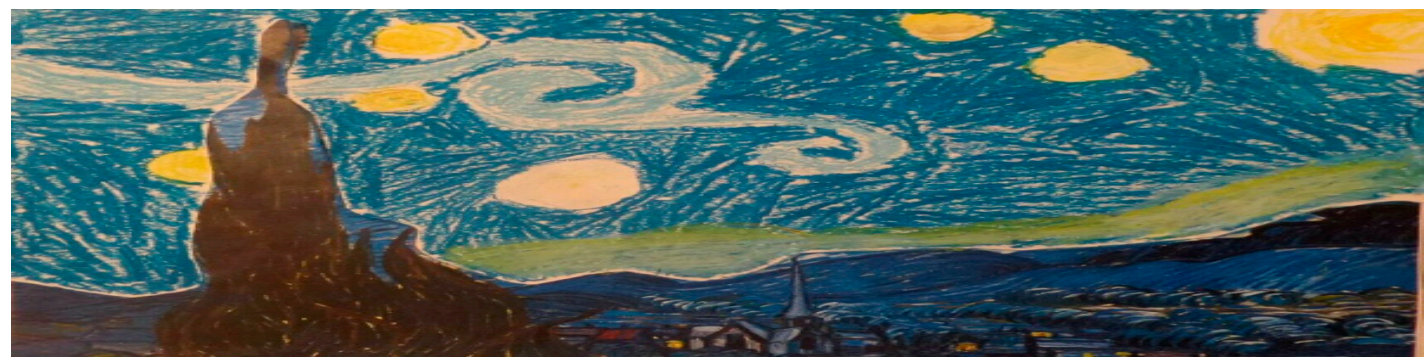

Figure 4. "Starry Night", sketch 4.

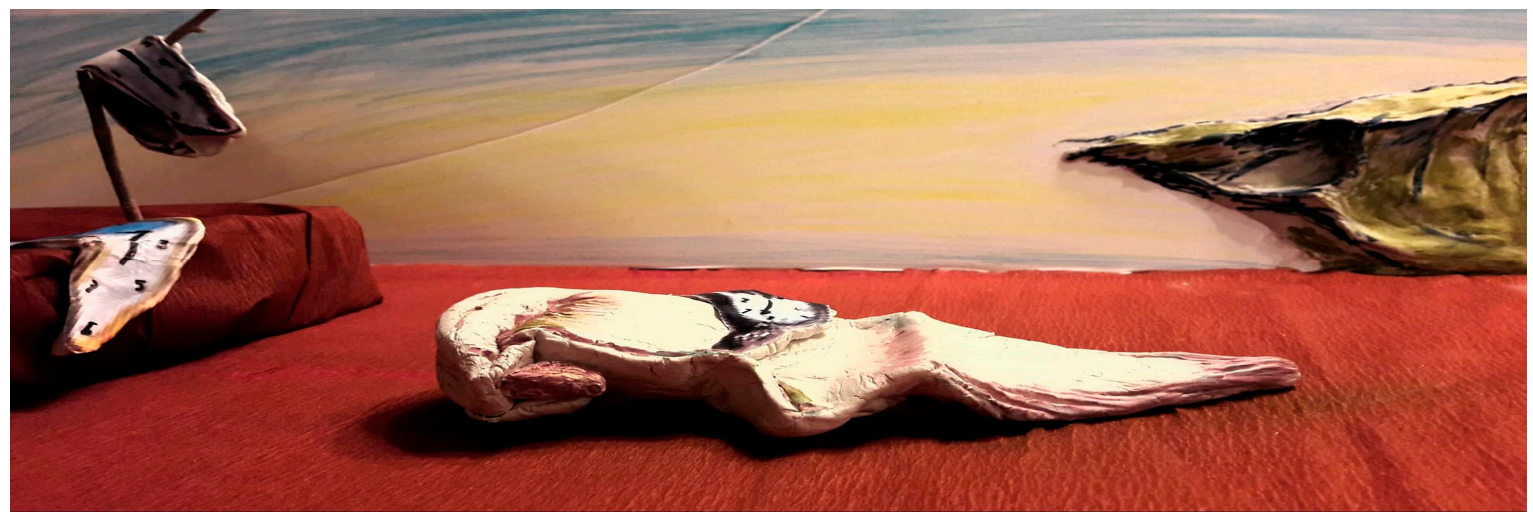

Figure 5. The maquette of the "The Persistence of the Memory".

The "Red Balloon" team attributed three dimensional features to the painting by using two cardboards. In the one cardboard, students painted the land on which the buildings are built and, on the other cardboard, they painted the buildings built onto it. In order to approach the original painting, they creased the cardboard with the buildings so as to give depth and placed it vertically on the other cardboard. The balloon was not painted as learners decided to add it digitally through Scratch.2 (Figure 6).

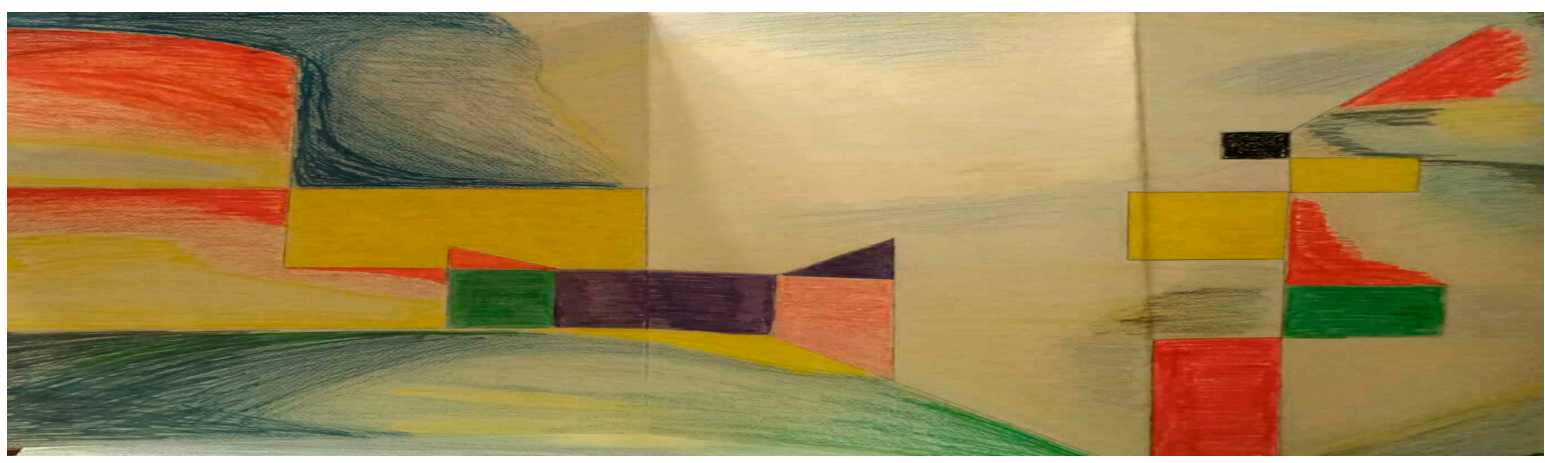

Figure 6. The maquette of "The Red Balloon".

The "Ship with the butterfly sails" team designed the ship and branches of trees as the mast and painted plenteous butterflies in different shapes. Learners placed the butterflies in different places of the cardboard and were taking photographs of them. They used the specific photos as backdrop for the digital story as, while adding the one photo after the other, they created the illusion that the big butterfly moves onto the story and makes the other butterflies move (Figure 7). 


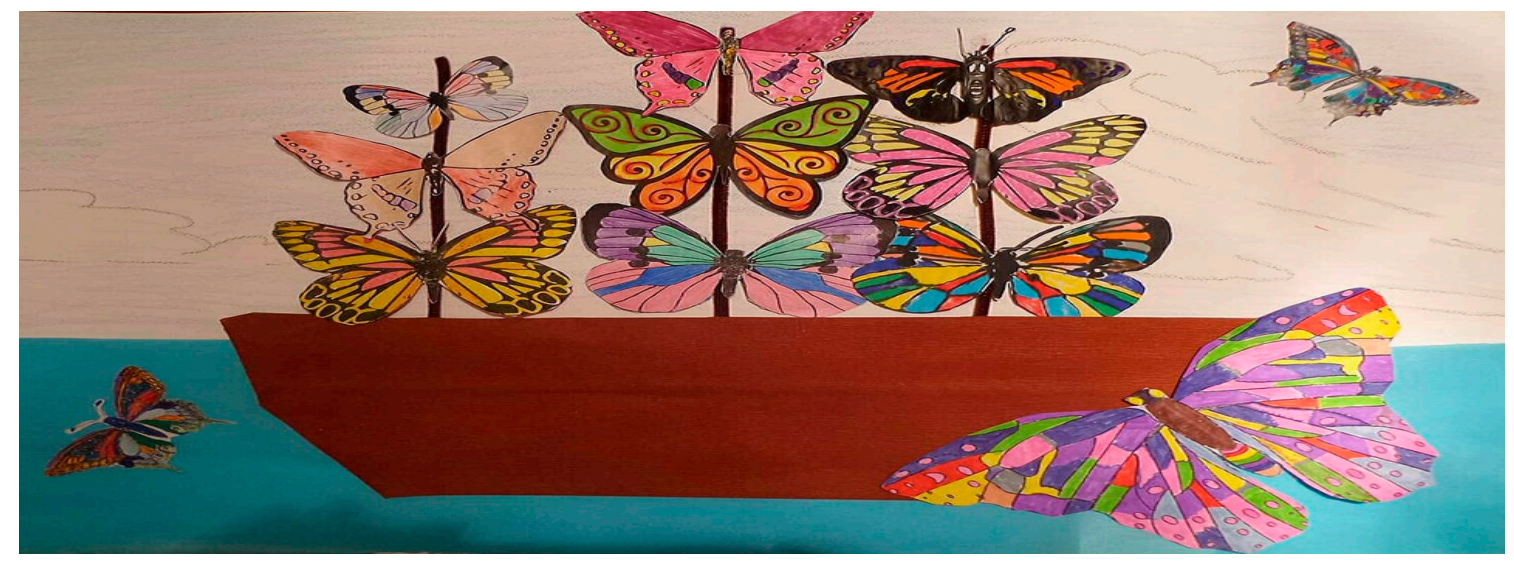

Figure 7. The collage of the "Ship with the Butterfly Sails".

Finally, the "Jeune fille endormie" team decided to make the sleeping girl in the Picasso painting gradually wake in their digital story. In order to achieve this, an outline of the original painting was designed with pencil omitting the eyes of the girl. The outlines were photocopied, and each student had to paint the painting and design the eyes of the girl at different phases (closed, partly closed, slightly open, open, and wide open). Photos of the paintings were digitally added to the story, thus creating the impression that the sleeping girl in the Picasso painting wakes up (Figures 8-10).

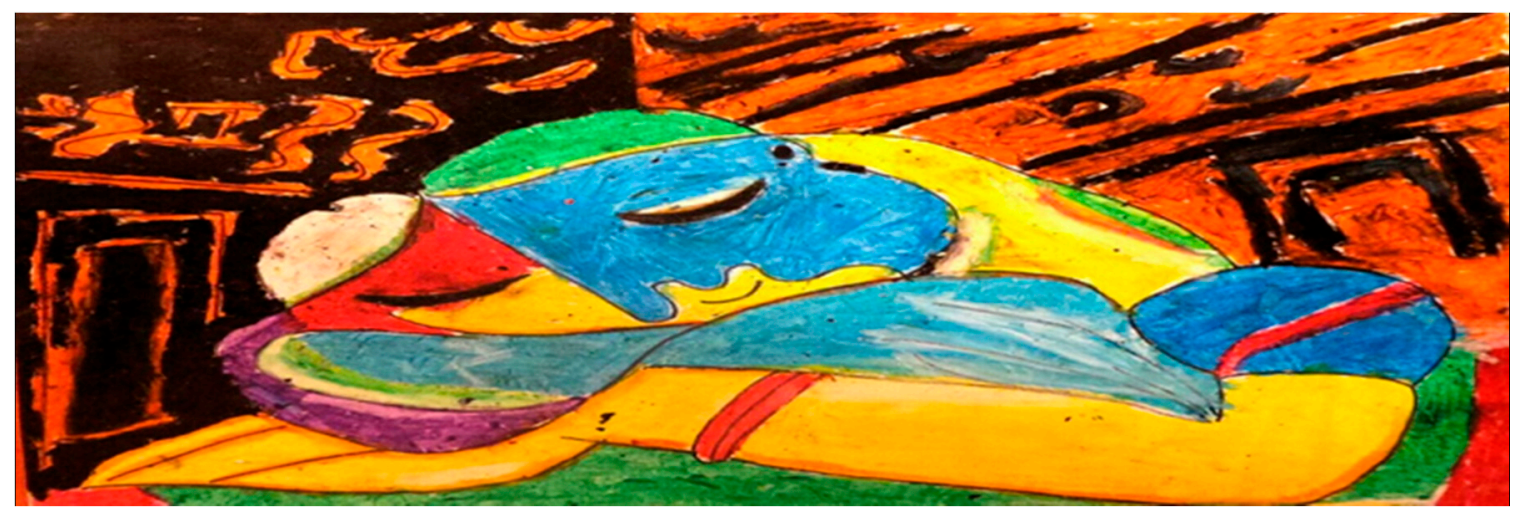

Figure 8. "Jeune fille endormie", sketch 1.

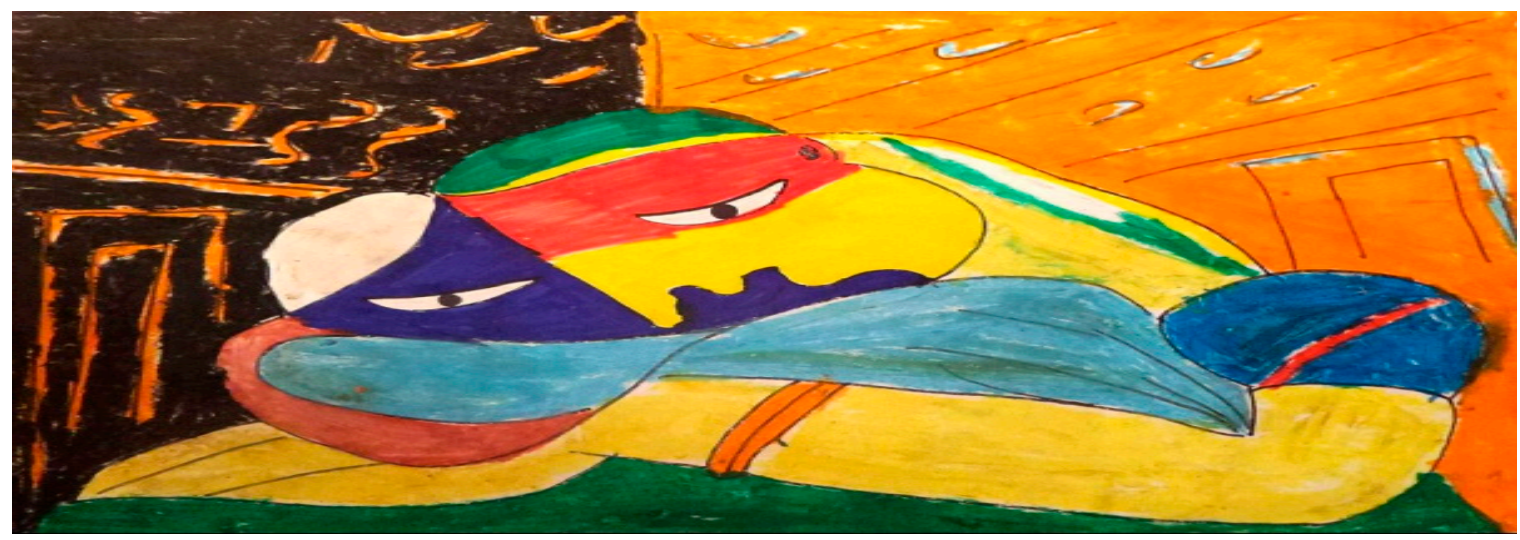

Figure 9. "Jeune fille endormie",sketch 2. 


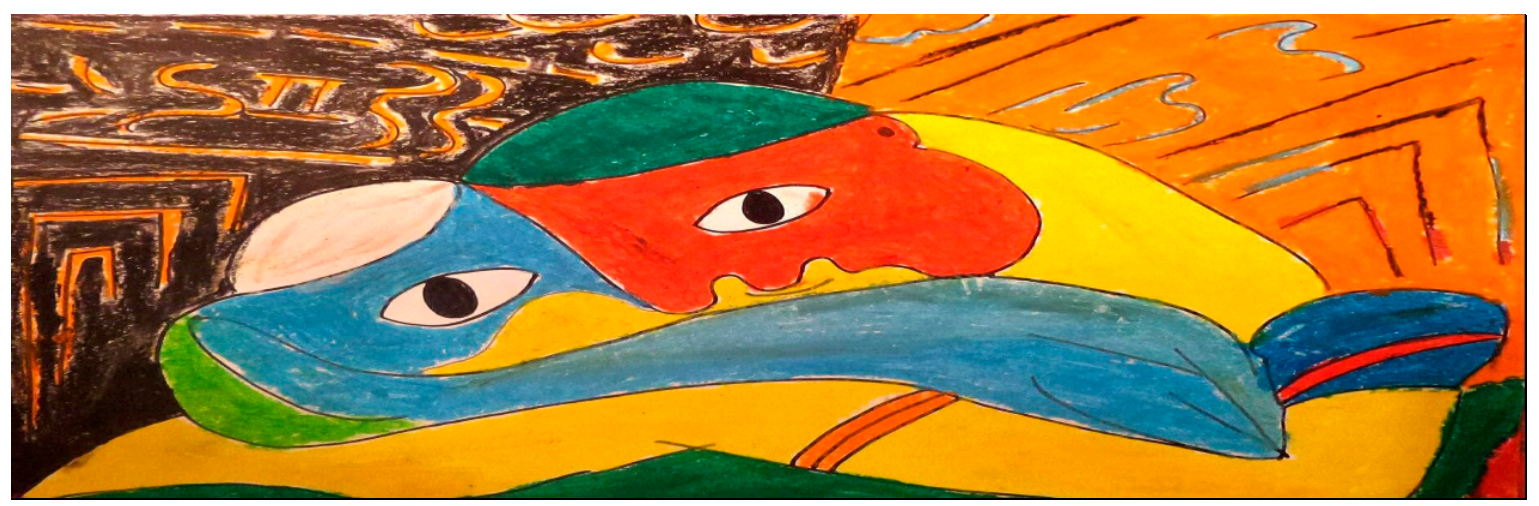

Figure 10. "Jeune fille endormie", sketch 3.

While recreating the famous paintings, learners got simultaneously engaged in scriptwriting. In specifics, learners of each class got divided into six teams with the learner who had assumed the "scriptwriter" role being the leader. In specifics, at that stage, learners started writing down the script to be recorded and narrated by a digital child who would act on each painting. According to the script, in the first part of the story, there is one digital human child wandering from painting to painting (backdrop) who presents the causes of the environmental destruction. In the second part of the story, a different digital child acts on one of the five paintings and expresses different thoughts about nature. Finally, in "The Meditative Rose", which is the last painting of the story, solutions to saving the earth are unveiled by all digital children gathered in the famous Dali's work of art.

During the next three weeks (4-22 December), after voice recordings had been implemented by the "narrators", the "coders" started working on the digital story. In cooperation with the ICT teacher along with ICT researchers, the "coders" divided each class into three groups. In the first week (4-8 December), each group used Audacity software in order to make adjustments on the audio material and synchronize it with the video. The other team photographed the creations to be used as the story backdrop and filmed a small video of the "Starry Night" painting they recreated three-dimensionally to be included in the digital story through the Video Movie Maker software. Finally, in the next two weeks (11-22 December) each team worked on the digitization of the story through Scratch.2 and the inclusion of the specific videos made through Scratch. 2 in the digital story created with Movie Maker.

In specifics, the photos (paintings) were uploaded on the Scratch. 2 software, and learners chose a Sprite from the Scratch.2 library. They exploited the coding potential provided by Scratch. 2 in order to give movement to the human being (being represented by the Sprite selected) who would narrate the causes of environmental destruction depicted in the paintings used as the backdrop of the story. Then, they inserted their videos into Movie Maker along with the voice recording files and the music selected (as an MP3 file) into Movie Maker.

The project was completed after the Christmas holidays (8-13 January) and was presented to students, parents, and teachers in the school assembly hall on Saturday 13 January 2018. The students who had undertaken the "scientific analysts" role were responsible for the presentation of the digital story. They first presented the video and then discussed scientific issues after they had gathered valuable information in cooperation with the physics teacher.

In specifics, students discussed the chaotic vortices detected in Van Gogh's painting while, in the Salvador Dali paintings, students talked about the globality of the earth since, through Scratch.2, the students placed a digital ship in the background of the painting and programmed it to become diminished while moving, until it disappeared. In the "Red Balloon" painting, they discussed the light analysis by performing a prism experiment, thus comparing the range of colors used in Klee's painting with the colors emerging through the prism experiment. In the "Ship with butterfly sails" painting, they talked about the butterflies' stages of growth and, finally, in Dali's "The Meditative Rose", they discussed how the rose petals develop according to the Fibonacci sequence. 


\subsection{Evaluation}

In the last stage, which lasted two weeks (15-26 January), learners were prompted to reflect on the final outcome, evaluate it, and provide and receive feedback by the teacher and their peers. They were prompted to evaluate the digital story creation process as well as the end story, and comment on how they collaborated and any difficulties they dealt with (Singhal 1997). While being involved in the evaluation process, learners became engaged in the learning process (Lambert 2013) and claimed "ownership" of their own work. Through reflective thinking of the whole process, learner autonomy was nurtured, which helps learners turn not only into independent learners, but also into lifelong learners themselves (Koufadi 2014). Finally, they were called to fill in an evaluation Google form, with criteria clarified to them at the planning stage, which acted as a reflective platform for both teachers and students (Karagianni 2014).

\section{Results and Discussion}

The analysis of the data collected, as they emerged through the observation process, the use of the reflective diary, and the two phases of interviews conducted to the learners, the teachers, and the principal before and after the completion of the digital story, paved the way for comparing the findings and drawing conclusions. What follows is an extensive presentation of the findings into three chapters, with reference to the aim of the research as well as the initial research questions.

\subsection{Critical Thinking}

What can be deduced from the research-based evidence is that digital storytelling greatly helped learners ignite their critical thinking. Worth mentioning is what the special education teacher mentioned in her interview. In specifics, she said the following:

"Actually, the whole process surprised me in a pleasant way. For me, the interest shown by all my students, including those who attend the Integration class, shocked me. For example, Eleni who seemed to have completely lost interest for the learning process, gradually started being activated within the group. After assuming the role of an artist-leader, her ideas about reconstructing the Starry Night painting and the movement of the stars with nails was indeed amazing. The feeling of satisfaction she had after she realized her teacher's and classmates' enthusiasm regarding her idea seemed to activate her in the learning process. She felt responsible for the final outcome which, in turn, made her fell precious and indispensable in her class. The feelings of responsibility and satisfaction were so powerful that made her overcome even her biggest fear. Despite her learning difficulties and problems she deals with in writing, she was quite active during scriptwriting ... "

According to those mentioned by the teacher in the specific extract, Eleni seemed to be gradually activated within the group. She got engaged in problem-solving regarding issues which kept emerging while implementing the project as her imagination kept igniting. The feeling of success she felt boosted her self-confidence, since she assumed an active role in various phases of the project, even in those where she considered herself weak. Worth noting is the fact that assuming the role of a group leader made her feel safe, responsible, and able to deal with her obligations. As a consequence, she designed and promoted her own course of action, thus acting as an autonomous, independent learner by activating high-order thinking skills.

The teacher's point of view was verified by Eleni herself. In specifics, she mentioned:

"I liked the project very much because we had to think how to do it."

At another point of the interview, she also mentioned:

"Firstly, I did not know what to do. It seemed difficult. Still, as time went by, I began coming up with and rejecting ideas." 
Eleni's words seem to coincide with the teacher's point of view. Helen utilized her imagination, and synthesized and developed her own ideas while suggesting and rejecting solutions. At the same time, through the information gathered from observation, the rest of the students were activated in a similar way.

While recreating the famous paintings with three-dimensional characteristics, learners came up with plenteous innovative ideas similar to Eleni's aforementioned one. A point also worth mentioning is that some learners came up with an original idea and the rest of the members of the group developed and perfected it. Throughout the whole process, teachers acted as guides and supporters by engaging learners in brainstorming while there were incidents during which discussion was initiated by learners themselves. An incident worth noting is that of Maria, who proposed recreating Dali's "The Persistence of Memory" on a maquette to be used as backdrop in the digital story. Students started unfolding their ideas regarding the most suitable materials to be utilized, as well as different techniques of working with the maquette.

Also, with regard to high-order thinking skills, the ICT researcher mentioned the following in his reflective diary (11 December 2017):

"Today, the second week of coding with the programming language Scratch.2 began. All students seemed to be focused on their goal. Every student started working with the Scratch.2 library, working at his/her own pace and rhythm and considering his/her own preferences. In particular, George managed to write a script where two different sprites move simultaneously. The team leaders are students who seem to be acquainted with Scratch. 2 and seem to be engaging with coding in their free time. There were also some students who despite the fact they had difficulty in coding, made suggestions which were considered by the team leader. All students seem to be promoting their ideas, thus creating a collaboration network".

In the light of this evidence, the obvious conclusion to be drawn is that the project promoted constructive learning which, in turn, fostered learners' imagination and critical thinking. George seemed to be working on something he relished at his own pace and rhythm. What can be deduced is that learners were active participants and claimed ownership of their work while expressing themselves and experimenting "in the construction of things not only for themselves but also for others" (Papadopoulou and Vlachos 2014, p. 250). They did not merely derive information from the web, but they analyzed, processed, classified, modified, compared new data in order to create new knowledge (Åberg 2014; Karagianni 2014; Papaefthymiou-Lytra 2014).

Additionally, regarding the scriptwriting phase, the teacher in charge mentioned the following in the interview:

"In my view, scriptwriting was a process unexpectedly creative and I would dare say moving. Pupils seemed to be sensitized by the paintings and even enchanted by their aesthetic excellence. The second part of the digital story was intended to provoke the audience's emotions and students made use of everyday routine instants in order to build the script. It reminded me of my childhood. Especially, the combination of music, paintings of these wonderful works of art, the children's voices with their wonderful narration touched deeply me..."

As clearly indicated from the aforementioned excerpt, learners engaged in purposeful and authentic writing as they got emotionally attached to the project content. They seemed to relish the writing process and, far from viewing it as a writing skills' assessment activity, they found their voice and discovered the art of writing. They engaged in process writing and discovered its recursive non-linear nature while demonstrating novel ideas through brainstorming, drafting, and redrafting (Frazel 2010; Ohler 2013; Robin 2008).

Conclusively, with reference to the first two stages of the project (preparation-implementation) learners' critical thinking was triggered, since learners were prompted to work based on two rudimentary axes (transversely and horizontally) and at two different levels (micro level-macro 
level). In particular, the painting reconstructions took place alongside scriptwriting (transversely), both promoting each other's implementation, while the other stages succeeded each other by passing on the torch to the leader of the next group to undertake (horizontally).

Regarding the two levels of its implementation, micro level referred to implementing a part of the stage (coding, script, craftwork, gathering of online information, selection of music) while macro level referred to the completion of the end product, which demanded team coordination and teachers' and learners' flexibility so that learners assembled all stages and produced the digital story.

Consequently, action taking place in a methodical manner, the ability to predict and deal with difficulties at a micro level (stage), and the combination of transversal and horizontal action required the overall contribution and activation of each team member, which would lead to dealing with any difficulties arising in the macro stage (final product). Even students who seemed to be isolated within the class because of learning difficulties (Eleni's case) developed new skills and hidden talents, thus contributing to the end product at their own pace. Learners were prompted to synthesize, analyze, and evaluate on a micro and macro level, according to the method which best suited them.

Worth noting is, also, that learners' critical thinking was fostered while presenting their digital story to the audience where students who assumed the role of scientific analysts played a pivotal role. In particular, the analysis of the story's central content and relevant scientific issues, such as the butterfly growth stages-Ship with Butterfly Sails, the chaotic vortices-Starry Night, the light analysis-the Red Balloon, the digital boat getting lost in the horizon-the Persistence of Memory, the Fibonacci sequence-The Meditative Rose, triggered the audience's as well as the students' interest regarding the particular scientific information. A finding worth mentioning is that after the presentation, learners started looking for further information on the specific issues and initiated relevant discussion in the classroom with the teachers. The school principal stated in the interview he gave:

"The presentation really surprised me. What we watched represents our culture, science, technology, biology and art and sends a clear message of respect which was for me the whole of our gut culture, science, technology, biology and art, oriented to a purpose that is totally on the side of man, since the message of respect for nature is essentially a message about the human future. The feedback given to children and to ourselves is very significant since the approached scientific issues using data drawn by nature"

In the light of the evidence provided by the observation findings, as well as the interviews conducted, the presentation of the digital story proved the extent to which digital storytelling can promote multi-faceted knowledge, creating stimuli of utmost importance. The power of the digital story, both through the aesthetic emotions it provokes through the blending of visuals and sound, and the experiential approach adopted as learners exploited it to analyze issues regarding our natural and technical world, triggered the teachers' and learners' interest for further engagement and action.

At this point, the role of the teachers is crucial. In particular, in order to mobilize students' critical thinking, they must design activities that take into account the academic and social profile of each learner (A $\gamma \gamma \varepsilon \lambda i \delta \eta \zeta$ 2012). Beginning, therefore, with activities that require simplistic mental processes at the level of recalling and applying knowledge, the learner must deepen mentally based on his own learning pace and potential. $\Pi \alpha \pi \alpha \nu \alpha \sigma \tau \alpha \sigma i o v(2017)$, taking Bloom's taxonomy into consideration, mentions that educators should design lesson plans which provide learners with opportunities to conquer the higher levels of critical thinking.

According to recent research, a digital story can work towards the aforementioned end. Aberg (2014) and $\Delta \eta \mu \eta \tau \rho \iota \alpha ́ \delta \eta \varsigma ~(2015)$ highlight the intrinsic motivation both learners and teachers exhibit. In addition, Ohler (2013) argues that digital storytelling, with the variety of tools it uses, is an instructional tool providing learners with equal learning opportunities and creates conditions for the cultivation of higher cognitive skills. Regarding the power of image, A $\mu \alpha v \alpha \tau i \delta \eta \zeta$ (2016), Kouvara et al. (2018), and Papadopoulou and Vlachos (2014) highlight how digital storytelling can help learners develop visual 
literacy, help them construct meaning through the critical reading of visuals, as well as aid them to access, interpret, and assess visuals in order to produce their own digital creation.

Regarding inclusive education, the digital story of the specific project seemed to motivate all learners (including the integration class learners). The collaborative model adopted, and its learner-centered nature led students, like Helen, to participate in all activities, even those involving higher cognitive levels of thought. The team seemed to work as a whole, where the idea of each student triggered the thought of the other, while the feedback received even by the students facing difficulties motivated them to approach deeper knowledge levels.

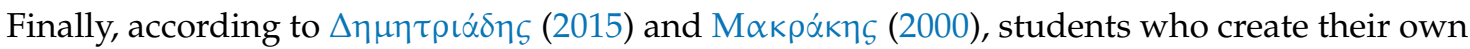
story learn to develop communication skills by asking, analyzing their views and the views of others, expressing their ideas through scriptwriting, while they learn to develop critical thinking and self-criticism, using even more complex forms of thought (analysis, synthesis, evaluation). Also, Barnes et al. (2007) argue that digital storytelling, through promoting higher-order critical thinking skills, can raise issues of diversity and multiculturalism. Finally, K $\lambda \iota \vee \alpha ́ k \eta$ (2012) claims that a digital story can act as an environment of critical learning, since the student is called upon to build knowledge and conquer it through the experiential approaches it provides.

\subsection{Learner Engagement}

The digital storytelling project ${ }^{3}$ seemed to have activated learners' critical thinking as well as their performance, since motivation for exploring and acquiring knowledge was created. Consequently, what can be deduced is that when the process of exploring and constructing knowledge is gravitated towards learners' needs, learner engagement emerges as a natural outcome of an active procedure and creative expression.

The teachers involved realized the aforementioned positive results regarding learner engagement and adopted a more learner-centered and cooperative approach. In specifics, the St 1 class teacher mentioned in her interview:

"What I realized while implementing the project was that the planning stage is of crucial importance. Precision in the planning stage will result in precision in the implementation stage. I began researching what fits each of my students. In the history lesson, I started using more videos and provide students with notes. I used intense visuals since many students were interested in the artistic part and I utilized material form museums I have visited. They liked the idea and their interest was raised ..."

In the light of this evidence, the specific teacher decided to adopt a different teaching approach considering the needs and interests of each student, having realized the positive impact of the project on learner engagement.

A point worth mentioning is that she seemed to reflect on the impact of the techniques used on her students, such as the use of personal photos and to adopt similar effective techniques. To be more specific, she realized that learners got more enticed when the presentation of visual material was combined with other elements, such as a personal testimony.

In a similar vein, the teacher of St 2 class mentioned in his interview:

“... the digital storytelling project helped me realize that I have to become more inventive and flexible so as to aid each learner to engage in the learning process. The key is not to try out things blindly but take your learners' personality into account. I began to enrich my lessons with more visuals and videos and I started using drama as a teaching method. Of course, this venture demands work at home but, finally, it is rewarding since you can enjoy an incomparable better lesson which learners enjoy. You must be prepared to apply new things, which even if they do not succeed, reconsider and start building again ..."

3 Available at https:// drive.google.com/file/d/10zOgp5FY2jWKLtbYYL8ZkQiO-uLB4gK6/view?usp=sharing. 
The specific teacher stressed that differentiation will be achieved only if learner needs are taken into account. He also integrated digital tools and techniques in his teaching methods, so as to provoke learners' interest and consider learners' individual preferences. He differentiated his teaching methods in a way that would allow him to reconsider and adjust them accordingly. It goes without saying that such an approach demands personal work, but can lead to creative learning within a pleasant school climate.

Similar results were rendered through the observation method, which also highlighted learners' interest to acquire and construct new knowledge. More specifically, the specific project led to the restructuring of the school climate as learners stared acting as researchers trying to construct knowledge. Worth mentioning is the fact that some learners differentiated what they stated in their second interview. For instance, Dimitra had stated in her first interview:

“... I like Language. It is my favorite subject."

After the completion of the project, she stated:

"... My favorite subject is Science. The teacher makes experiments and we discuss about the lesson. It becomes more pleasant..."

As a consequence, the results rendered both by the interviews conducted and the observation method highlight that the specific project provoked learners' interest to explore and construct new knowledge, and led teachers to adopt new teaching techniques that sustain and enhance learners' interest. The positive climate created in the school unit seems to have led educators to realize that there are not indifferent pupils, but rather indifferent ways of teaching and ineffective approaches. This awareness appears to be due to the fact that this project has acted as an experiential form of education since teachers have realized, in practice, the positive effects of differentiation, thus creating an inclusive learning environment.

The value of training in inclusive education is, also, underlined by other contemporary researchers. According to $A \gamma \gamma \varepsilon \lambda i \delta \eta \zeta$ and $\Sigma \tau u \lambda\llcorner\alpha \gamma$ ov (2011), a key issue raised is teacher training, and it is important this takes place within the school unit. Unfortunately, in Greece, where training is mainly based on fragmentary seminars and conferences, the application of inclusive methods is often superficial (A $\rho \beta \alpha v^{\prime} i \tau$ and K $\alpha \tau \sigma \alpha \rho o ́ \zeta$ 2016). In addition, it does not target learners' needs so as to create further incentives for learning and social engagement.

The aforementioned beliefs about learners' needs are also espoused in modern educational research. In particular, Ainscow et al. (1999) and Messiou (2006) claim that differentiated instruction should consider all learners' needs, the "children's voices". In order to give prominence to children's voices and adopt a more inclusive differentiation, the appropriate preparation is of crucial importance

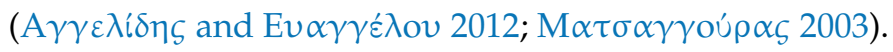

Additionally, regarding the results of diversified instruction on the school climate, Frazel (2010) advocates that the adoption of a structured teaching strategy orientated towards the uniqueness of students enhances learners' performance, while Sadik (2008) claims that learners' self-confidence is boosted. Conclusively, according to Frazel (2010), cooperative techniques that emphasize experiential learning enhance learners' performance and affect their social skills.

\subsection{Collaboration Networks}

The last research question refers to collaboration networks. In specifics, the positive results rendered throughout the project with regard to learners' and teachers' engagement seemed to promote the creation of collaboration networks.

Teachers assumed the role of supporter and coordinator, thus promoting collaboration among students, while teachers seemed to apply collaboration techniques on lessons where learners were accustomed to working individually. In math, learners were divided into the same groups that had been created during the project so that all team members support each other. Although, at first, strong 
and novice students were placed into the same team, groups were modified because weak students became inactive within the group. Then, teachers adopted a new model where group members were equal, while the problems they had to deal with was of a different level of difficulty. One of the teachers stated:

"... The initial method of group forming failed as the weak students and especially the special integration class students could not work within the groups. However, we were not discouraged. We formed new groups according to the method I mentioned. The new method demanded hard work as we had to prepare the appropriate activities which would promote all learners' cognitive level within the groups. In order to achieve this, both teachers cooperated on a daily basis while the integration class teacher greatly helped us supporting learners when necessary ... "

According to what the specific teacher stated, teachers relished the benefits of collaborative learning and adopted the specific model while teaching core subjects. In math, teachers created a collaboration network so as to form learner groups in an effective way. They became more flexible and willing to modify their teaching methods aiming to form effective groups in collaboration with the special education teacher.

A similar course of action was taken in other subjects as well, thus rendering positive results and activating learners who also helped their classmates. In specifics, all learners contributed to the final outcome as each learner provided information to be processed by the group and lead to the appropriate solution. Finally, learner interviews revealed that learners were enthusiastic about the new teaching model according to how they expressed their feelings about the process adopted.

The aforementioned beliefs with reference to the benefits of collaborative learning are espoused by contemporary researchers. In specifics, $A \gamma \gamma \varepsilon \lambda i \delta \eta \zeta$ and $A \beta \rho \alpha \mu i \delta$ ov (2011) advocate that knowledge through collaborative learning stems from its critical consideration, since learners process it through different viewpoints. In a similar vein, Frazel (2010) and Sadik (2008) claim that collaboration provides learners and teachers with the appropriate feedback so that they work in an active and methodic way within the groups. Finally, according to A $\gamma \gamma \varepsilon \lambda i \delta \eta \zeta$ (2012) and Messiou (2006), when learners take initiatives within the group, they define the way teachers are going to take action. As a consequence, learners lie at the top of the learning process and lead teachers to take action.

Regarding leadership, foundations for a new collaboration network were created between the teachers and the school principal while implementing the digital storytelling project. The first researcher stated in her reflective diary (14/02/2018):

"Today, the school principal seemed to more resilient in his views in the council. He attentively listened to what teachers suggested regarding piloting the model of co-education and decided to support them"

With reference to collaboration, the principal stated:

"To be honest, the project was welcomed by parents, teachers and students which led me to reconsider some of my views. I decided to provide teachers with more freedom so that they act accordingly with their students. Schools should promote learning and this cannot be achieved when knowledge is imposed on the learner. At first, I believed that such innovations cannot be realized in the context of the centralized character of Greek education. However, through the project I realized that the required flexibility can ultimately come through collective action. I will dare to adopt a collaborative course of action so that we can all find ways to creatively build knowledge..."

Considering the aforementioned excerpts, the principal seemed to be trying to build bridges with students and teachers because of the feedback he received from the results yielded by the project. The acceptance of the project by the class as a whole has probably worked in such a way that made him perceive the value of cooperation and its contribution to issues that, if dealt through individual action, seemed impossible to be implemented. 
The above data are also verified through the observation method. In particular, during observation, the principal seemed to get engaged in dialogue with the teachers, parents, and pupils, providing them with more and more responsibilities. At the same time, the teachers started approaching the director and facilitating him on issues related to the school unit while students started building better relationships with their principal.

Conclusively, the aforementioned viewpoints regarding leadership which will promote collaboration between principals and school units are also espoused by other researchers, too. In specifics, $A \gamma \gamma \varepsilon \lambda i \delta \eta \zeta$ and Ev $\alpha \gamma \gamma \varepsilon$ é ov (2012) discuss the future leader in their research, presenting a principal who can identify barriers, assign teachers with the appropriate duties, and provide them with freedom of action and expression.

It is essentially a restructuring of the leadership, according to which all the decisions of the leadership are made with the learner being at the base of the learning process (Ainscow et al. 2012). Such a form of reversed leadership (bottom-up) requires coordination, cooperation, and freedom of expression and creation (A $\gamma \gamma \varepsilon \lambda i \delta$ ov 2011).

This shift of leadership, with the student being its base and reference point, is a basic precondition for inclusive education, as indicated by research. In particular, the specific project, by providing various ways of approaching knowledge, offered learners various opportunities to participate democratically within the groups, while their ideas effectively guided its implementation.

The aforementioned point of view regarding distributed leadership in issues related to inclusive education is also espoused by other researchers. Ainscow et al. (2012) argue that recent research shows that the progress made in treating pupils as key members of the school is unfortunately low, while $A \gamma \gamma \varepsilon \lambda i \delta \eta \zeta$ (2012) argues that if we are interested in inclusive leadership, the student must

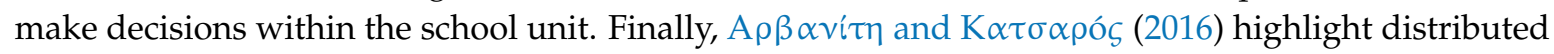
leadership and school networks as key components in school.

\section{Conclusions}

Through the diverse stimuli triggered by digital storytelling, which emerged from many different directions instead of just the educator's judgment, it was evident that a dialectical relationship between students and educational methods was established, while an inclusive shift took place within the school unit. However, these results only concern the context of the specific school unit and cannot be generalized, since the sample is not representative and the research's qualitative character leaves no room for generalization. The aim of the specific research is the in-depth study of the specific research framework so as to yield data to a great extent.

A point worth mentioning is that future researchers should enrich this research with quantitative data. Also, given that this research is limited to a single class of a school unit, it is suggested that the research be conducted in the other classes of the school so that the two-way effects between the learners and the school unit are better investigated. At the same time, implementing the project on many classes of the school unit would be more efficient in order to build a more sophisticated picture of the school under research. Additionally, although the research lasted 7 months, it should be extended, especially after the creation and completion of the digital storytelling project, in order to increase the validity of the results related to its impact on the school unit. Conclusively, similar projects related to diversity, interculturalism, and positive sciences could be conducted based on the same inclusive philosophy, while similar research could be implemented on the other levels of primary, secondary, and tertiary education.

Author Contributions: T.K.K. and S.A.K. perceived the concept, designed, selected data and participated in each phase of the project and the research. Also, they undertook the writing of the study. C.V.K. participated in the research as an observer only in the coding part with Scratch2. E.C.S. and V.S.V. had the role of supervisors and advisors throughout the research. 
Funding: This research was funded by the STAVROS NIARHOS FOUNDATION under program: Design and implementation of a blended learning course on visual programming: "Code-Create-Learn with Scratch.2" of the Hellenic Open University, Greece.

Conflicts of Interest: The authors declare no conflict of interest.

\section{References}

Åberg, Ewa S. 2014. Children's Story Making with Digital Technologies: Tool-mediated Activities in a Preschool. Bachelor's Dissertation, University of Gothenburg, Gothenburg, Sweden, September 4.

Ainscow, Mel, Tony Booth, and Alan Dyson. 1999. Inclusion and Exclusion in Schools: Listening to Some Hidden Voices. In Inclusive Education: International Voices on Disability and Justice. Edited by Keith Ballard. London: Falmer Press, pp. 139-51.

Ainscow, Mel, Alan Dyson, Sue Goldrick, and Mel West. 2012. Making Schools Effective for All: Rethinking the Task. School Leadership \& Management 3: 197-213.

Barnes, Kassandra, Raymond Marateo, and Pixy Ferris. 2007. Teaching and learning with the net generation. Innovate: Journal of Online Education 3: 1-8.

Booth, Dianna L. 2002. Project Work, 2nd ed. New York: Oxford University Press.

Czarnecki, Kelly. 2009. How digital storytelling builds 21st century skills. Library Technology Reports 45: 15-19.

Dickins, Paulina R., and Kevin Germaine. 2014. Managing Evaluation and innovation in Language Teaching: Building Bridges. London: Routledge.

Dochy, Filip, Segers Mien, Bossche Pit, and Gijbels David. 2003. Effects of problem-based learning: A meta-analysis. Learning and Instruction 13: 533-68. [CrossRef]

Frazel, Midge. 2010. Digital Storytelling: Guide for Educators. Washington: ISTE.

Jenkins, Martin, and Jo Lonsdale. 2007. Evaluating the Effectiveness of Digital Storytelling for Student Reflection. Paper Presented at the Conference, ICT: Providing Choices for Learners and Learning, Singapore, December 2-5.

Kajder, Sara, Glen Bull, and Susan Albaugh. 2005. Constructing Digital Stories. Learning E Leading with Technology 32: 40-42.

Karagianni, Evangelia. 2014. Teacher development and coll@bor@tion. Research Papers in Language Teaching E Learning 5: 87-109.

Karkoulia, Kostoula C. 2016. Teachers' attitudes towards the integration of Web 2.0 tools in EFL teaching. Research Papers in Language Teaching and Learning 7: 46-74.

Koufadi, Efthymia. 2014. Integrating Computer Mediated Communication (CMC) and Online Networking in the teaching of English as a foreign language in high school. Research Papers in Language Teaching \& Learning 5: 199-222.

Kouvara, Theodora, Christoforos Karachristos, Elias Stavropoulos, and Vassilios Verykios. 2018. Children's Voice and School Improvement: The Role of Technology in the Inclusive School of the Future. Unpublished manuscript, last modified November 13. Microsoft Word File for Croatian Journal of Education.

Kouvara, Theodora, Stavroula Karasoula, Christoforos Karachristos, Elias Stavropoulos, and Vassilios Verykios. 2018. Technology and School Unit Improvement: Researching, Reconsidering and Reconstructing the School Context through a Multi-Thematic Digital Storytelling Project. Paper Presented at the WEI International Academic Conference on Education, Teaching and Learning, Boston, MA, USA, August 1-3.

Lambert, Jameson. 2013. Digital Storytelling: Capturing Lives, Creating Community. London: Routledge.

Lee, Kuang W. 2000. English Teachers' Barriers to the use of Computer-assisted Language Learning. The Internet TESL Journal 6: 1-8.

Legutke, Michael, Thomas Howard, and Candlin Christopher N. 2014. Process and Experience in the Language Classroom. London: Routledge.

Lincoln, Yonna S., and Egon G. Guba. 1985. Naturalistic Inquiry. Newbury Park: Sage, vol. 75.

Messiou, Katerina. 2006. Conversations with Children: Making Sense of Marginalization in Primary School Settings. European Journal of Special Needs Education 21: 39-54. [CrossRef]

Miles, Matthew, and Michael Huberman. 1994. Qualitative Data Analysis: An Expanded Sourcebook. Arizona State University: Sage.

November, Alan. 2008. Web Literacy for Educators. London: Corwin Press. 
Ohler, Jason B. 2006. The world of digital storytelling. Educational Leadership 63: 44-47.

Ohler, Jason B. 2013. Digital Storytelling in the Classroom: New Media Pathways to Literacy, Learning, and Creativity. London: Corwin Press.

Papadopoulou, Sevasti, and Kosmas Vlachos. 2014. Using digital storytelling to develop foundational and new literacies. Research Papers in Language Teaching \& Learning 5: 235-58.

Papaefthymiou-Lytra, Sophia. 2014. L2 Lifelong Learning/use and New Media Pedagogies. Research Papers in Language Teaching E Learning 5: 16-33.

Richards, Rhonda T. 1998. Infusing technology and literacy into the undergraduate teacher education curriculum through the use of electronic portfolios. THE Journal (Technological Horizons in Education 25: 46-50.

Robin, Bernard. R. 2008. Digital storytelling: A powerful technology tool for the 21st century classroom. Theory into Practice 47: 220-28. [CrossRef]

Sadik, Alaa. 2008. Digital storytelling: A meaningful technology-integrated approach for engaged student learning. Educational Technology Research and Development 56: 487-506. [CrossRef]

September, Sean C. 2008. Educator Training and Support for Inclusive Education. Ph.D. Dissertation, University of Zululand, Zululand, South Africa, April 16.

Sifakis, Nikos, and Athina Georgoutzou. 2004. Language Leaning Skills EMaterials (Oracy and Literacy). Patra: Hellenic Open University.

Singhal, Meena. 1997. The Internet and Foreign language Education: Benefits and Challenges. The Catesol Journal. Available online: http:/ /iteslj.org/Articles/Singhal-Internet.html (accessed on 12 December 2017).

Teehan, Kay. 2006. Digital Storytelling: In and Out of the Classroom. Available online: https:/ /books.google.gr/ books?id=MarAZOtMKC0C\&lpg=PA1\&ots=XVf7KR0Xtn\&dq=).\%20Digital\%20storytelling\%3A\%20In\% 20and $\% 20$ out $\% 20$ of $\% 20$ the $\% 20$ classroom\&lr\&hl=el\&pg=RA1-PR1\#v=onepage\&q\&f=false (accessed on 2 December 2017).

Thorne, Richard E., and Garry Thomas. 2007. Herring and the "Exxon Valdez" oil spill: an investigation into historical data conflicts. ICES Journal of Marine Science 65: 44-50. [CrossRef]

United Nations. 1989. Convention of the Rights of the Child. Available online: http://www.un.org/documents / ga/res/44/a44r025.htm (accessed on 10 November 2017).

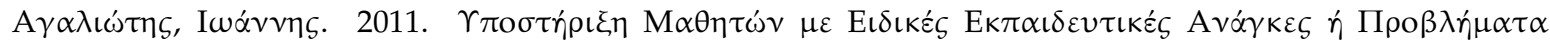
$\Sigma v \mu \pi \varepsilon \rho \iota \varphi о \rho \alpha ́ s$. Working paper, Department of Educational and Social Policy, National Documentation Centre, University of Macedonia, Thessaloniki. Available online: http://reader.ekt.gr/bookReader/ show /index.php?lib=EDULLL\&item=1124\&bitstream=1124_01\#page/1/mode/2up (accessed on 10 November 2017).

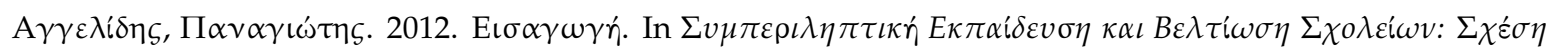

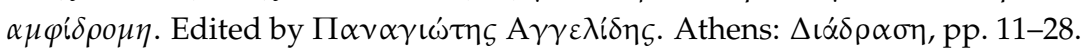

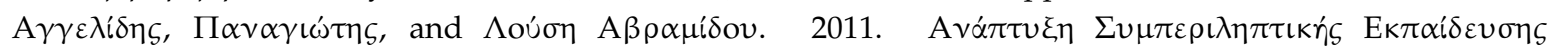

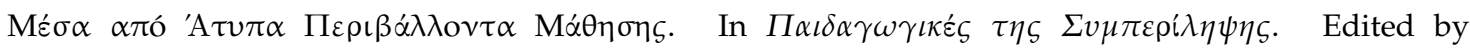
$\Pi \alpha \vee \alpha \gamma \iota \dot{\omega} \tau \eta \zeta$ A $\gamma \gamma \varepsilon \lambda i \delta \eta \zeta$. Athens: $\Delta \iota \alpha \dot{\delta} \rho \alpha \sigma \eta, \mathrm{pp} .17-42$.

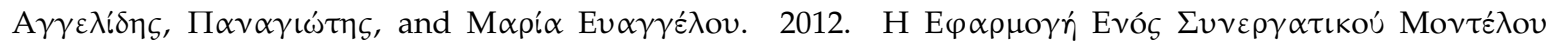

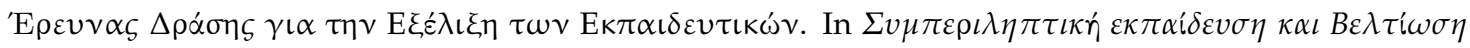

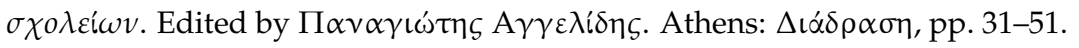

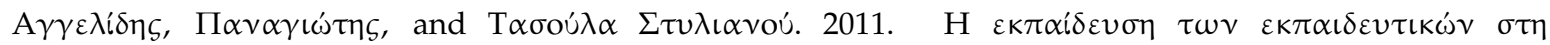

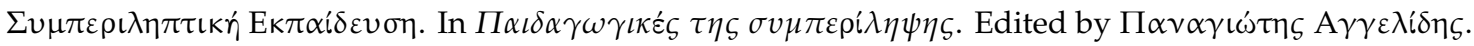
Athens: $\Delta \iota \alpha ́ \delta \rho \alpha \sigma \eta$, pp. 191-218.

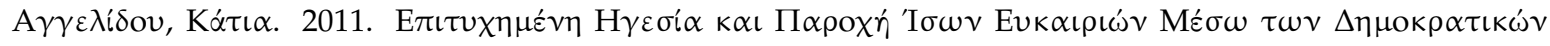

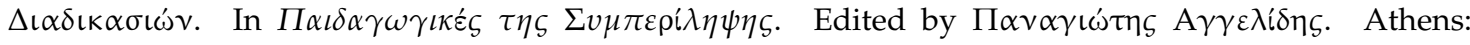
$\Delta \mathrm{\iota} \alpha \dot{\delta} \rho \alpha \sigma \eta$, pp. 163-90.

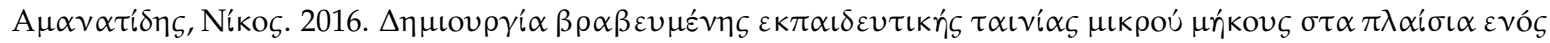

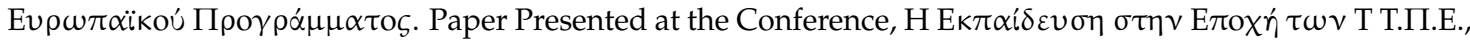
Athens, Greece, November 5-6.

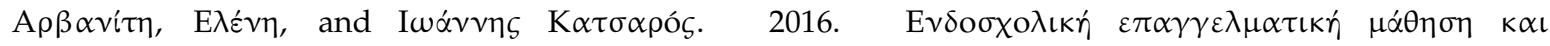

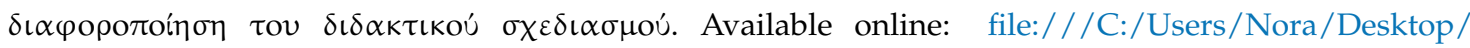
paperArvaKats16OCT15final.pdf (accessed on 24 April 2017). 


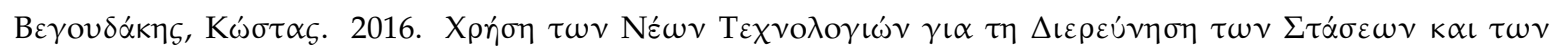

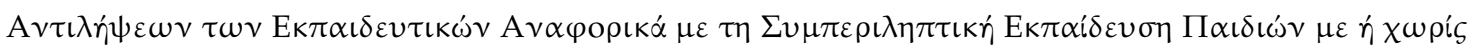

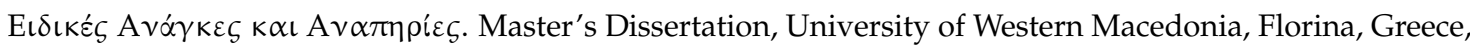
June 17.

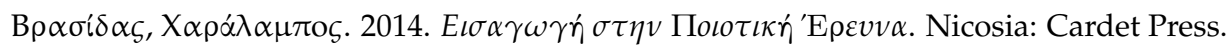

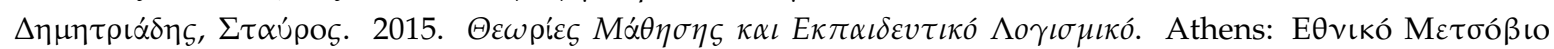
По $\lambda v \tau \varepsilon \chi v \varepsilon i ́ o$.

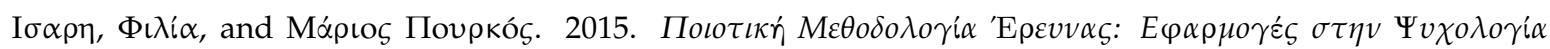

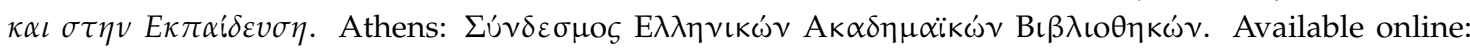
https:/ / repository.kallipos.gr/handle/11419/5826 (accessed on 4 December 2017).

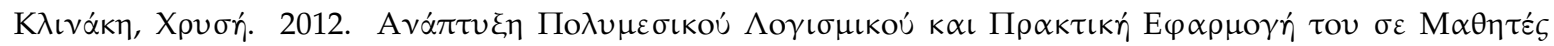

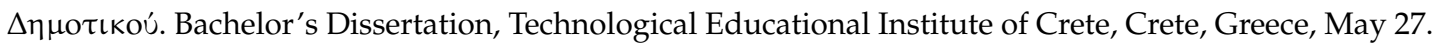

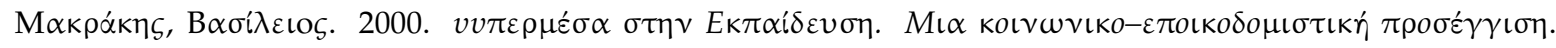

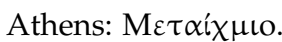

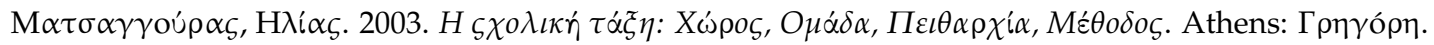

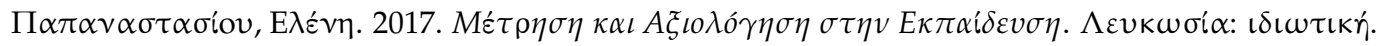

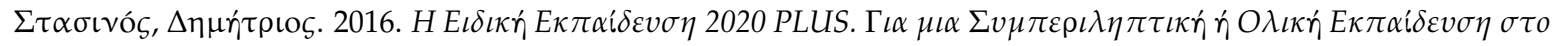

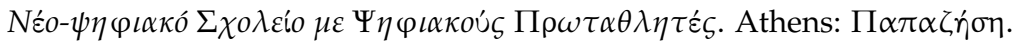

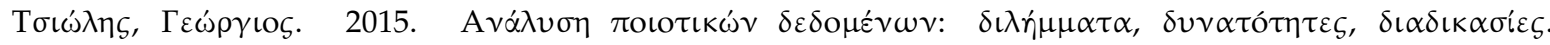

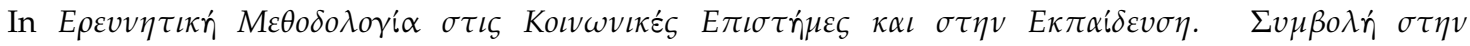

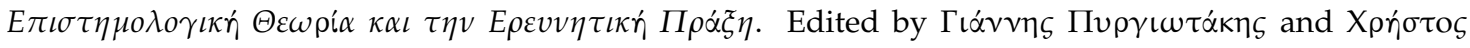

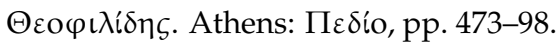

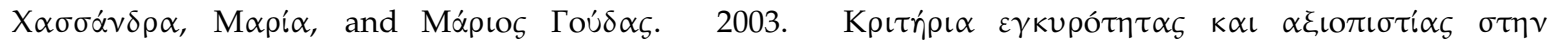

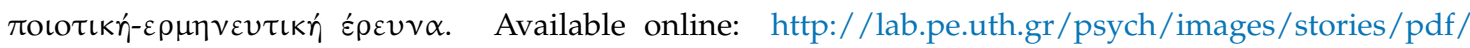
various/kritiria_egyrotitas_kai_aksiopistias_stin_poiotiki_ereyna.pdf (accessed on 5 January 2018).

(C) 2019 by the authors. Licensee MDPI, Basel, Switzerland. This article is an open access article distributed under the terms and conditions of the Creative Commons Attribution (CC BY) license (http:// creativecommons.org/licenses/by/4.0/). 